\title{
Identification of Sweet Spots and Seismic Fractures in Tight Gas and BCGS Reservoirs
}

Rogério Santos - Petrobras, Jose Lira - Petrobras, Arnaldo Tanaka - Petrobras; Julio Carvalho - Petrobras;Jose Ferrer Petrobras; Frank Bulhoes - Petrobras e Gleidson Ferreira - Petrobras

Copyright 2019, SBGf - Sociedade Brasileira de Geofísica

This paper was prepared for presentation during the $16^{\text {th }}$ International Congress of the Brazilian Geophysical Society held in Rio de Janeiro, Brazil, 19-22 August 2019.

Contents of this paper were reviewed by the Technical Committee of the $16^{\text {th }}$ International Congress of the Brazilian Geophysical Society and do not necessarily represent any position of the SBGf, its officers or members. Electronic reproduction or storage of any part of this paper for commercial purposes without the written consent of the Brazilian Geophysical Society is prohibited.

\begin{abstract}
Seismic identification of fractures and sweet spots in tight gas reservoirs (TGR) and more specifically in basincentered gas systems (BCGS) using conventional 3D data is a challenge to its intrinsic resolution, especially in land surveys, where noise levels are generally high. Methods of detection of structural continuities and discontinuities, mainly faults, have been described in the literature for the detection of fractures, with different levels of success. Amplitudes and their attributes for geometric and textural interpretation are applied to predict gas reservoirs and brittle zones. Over the past 40 years, different seismic techniques have been developed to identify fractured regions and several processes applied for regions where low permeability gas reservoirs are expected. TGR related to some of the largest natural gas resources are considered yet to find around the world. Once identified such reservoirs, the main challenge for gas production is the low permeability of the rocks. Their petrophysical facies may show important variations related to the permeability due to heterogeneities in the spatial distributions of their natural fractures. Knowledge about the occurrence of natural fractures can help to define the sweet spots, which can vary along a basin, and optimize the positioning of producing wells. Several geological parameters to explain the performance of the best producers have been observed by a large number of authors. Some of these parameters can be supported by 3D seismic amplitudes in their assessments. In this work are presented some concepts of seismic amplitude interpretation that can be used on the definition of sweet spots associated to the best amplitude facies of TGR and BCGS with the largest probability of understanding fracture networks that can be key factors in the control of their permeabilities and conditions for production stimulation.
\end{abstract}

\section{Introduction}

Meckel and Thomasson (2008) describe TGR having some peculiar characteristics: higher pressure; greater thickness of reservoir; better reservoir quality, or better facies; a reservoir with good primary porosity and permeability encased within the tighter host rock; leached porosity zones caused by deep diagenesis; presence of fractures or a greater abundance of fractures and conventional traps within the pervasive gas accumulation. Those authors formulate some questions about doubts to define such reservoirs: Are sweet spots simply reservoirs found in normal geologic stratigraphic and structural traps; or are sweet spots formed where various processes have enhanced the reservoir quality of gas-saturated tight sandstones; or still and as they believe, are both processes at work in different basins and different settings, making the job of the explorationists more difficult because of the need to examine all the variables discussed herein.

Here in this work, we look for some partial answers for these complex questions involving each TGR spread out around world. Naturally, the sum of all small answers can lead to the effective and economic exploration of this important resource yet to be found and produced and conventional 3D seismic amplitudes can be effectively used and interpreted to reduce uncertainties and help in the definition of sweet spots and natural fractures in TGR. For practical examples, is adopted the same seismic analysis standard for TGR classified simply as tight gas sands or those considered as BCGS, due their similarities in the seismic responses from their facies and structural elements.

\section{Theory and Methods}

According to Law (2002), BCGS can be characterized by accumulations in a certain region saturated by gas, abnormally pressurized, generally not having a downdip water contact, and defined by low permeability reservoirs. The author groups such accumulations that vary between: isolated reservoirs; isolated reservoirs with a few meters of thickness and multiple reservoirs stacked, the latter being able to have many hundreds of meters of thickness. These definitions are very interesting for who works with 3D seismic data because they can face the lack of intrinsic resolution of $3 \mathrm{D}$ seismic amplitudes, grouping facies and fracture zones with the capacity of seismic data distinguish responses related to events from isolate reservoirs to stacked reservoirs. Besides amplitudes, for a more complete seismic solution following Law's classification it is also important evaluations of seismic velocities that is not the goal of this paper.

Another important characterization of BCGS is presented by Popov et al (2000), which follows some parameters that serve as a link between that which can be defined from information in well scales and the correlated seismic scales as equivalent layers. They state 12 characteristics of BCGS characterization, of which we identify 8 that can be supported by seismic 3D amplitudes for BCGS analysis: Reservoirs occur in large geographic areas (tens to hundreds of $\mathrm{km}^{2}$ ), often occupying the central and deepest part of the sedimentary basins; they do not have water contacts (downdip), and hydrocarbons do not occur 
in situations with gas floating above water; reservoirs are abnormally pressured, over or under, and can be overburden by rocks with normal pressures; source rocks are in the vicinity of reservoirs; structural and stratigraphic traps are of less importance; compartments may exist and may generally form sweet spots; multiple fluid phases contribute to the development of the seal in reservoirs.

The first seismic study looking for attributes to differentiate fractures and facies usind $3 D$ data can be counted to Taner et al (1979) with the use of complex traces. From that time to now, hundreds or even thousands of papers were published in these senses.

When TGR and BCGS are seismically interpreted looking for detection of over or underpressured zones, as well as their reservoir facies and thicknesses, the major challenge is to understand the possible vertical and lateral seismic resolution able to differentiate them from a nonfluid system. They build non-trivial scenarios for exploration strategies, and normally we use tools traditionally developed just for the needs of conventional reservoirs. In this context, it is fundamental to apply methods that impact the analysis of seismic amplitudes in the search for subtle petrophysical variations that lead to relative and small seismic anomalies and that indicate a reduction (or an increase) of the impedance contrast in regions with zones of anomalous pressures, which should always be verified in drilled wells, or based on analogs. Also important are the seismic aspects correlated to the expectation of success in the detection of fracture zones, such as those translated by post-stack attributes of curvature and coherence. For BCGS, another critical factor for the technical success of seismic support, is a very good relative seismic response, associated to the real existence of gas in paleogeograpically distributed environments and, mainly, in its spatial physical boundaries (source rock, migration pathways, contact of seals, reservoirs limits and fluidic traps). The expectation of such seismic success depends on the presence of the gas in this distribution and is based on the effective reduction of the original elastic constants (compressional modulus - $\mathrm{P}$ wave) in the analyzed geological environment. Quantitatively, this expectation is based on information (and its quality) from tests and well logs sampled in a particular BCGS and that this data can be effectively transposed to the seismic. The differentiation of a given gas accumulation, such as a BCGS system (necessarily abnormally pressured), from other composed of traditional, usually pressured, low-permeability reservoirs is fundamental for understanding the expectations derived from seismic record and in order to respond to any petrophysical variation that is detectable by such seismic data. Popov et al. (2000) complement that for a given gas accumulation to be classified as a real environment of BCGS it is necessary records of pressures located dispersely in vast areas of this accumulation and the response of $3 \mathrm{D}$ seismic needs to follow this logic consistently.

Particularly, the entire expectation of success of the seismic support to the BCGS characterization is strongly related to the quality of the available data, but it is also very closely associated with the seismic analysis and processing methodologies. in general, are adopted for traditional data in conventional petroleum systems. A detailed analysis and review of traditional seismic data processing and interpretation methods for BCGS systems should be performed. Another key part of the oil industry in exploiting such accumulation is the reservoir element.

On the one hand, if perforated wells define well the types, thicknesses, petrophysics, saturations and depositional models of a reservoir, on the other hand, their spatial delimitations and distributions (mainly vertical individualization of bodies) and volumetry depend heavily on the information of the 3D seismic data.

In the majority of the cases described worldwide for the production of BCGS, they are stacked siliciclastic reservoirs, forming large thicknesses, but always individualized by groups of different genetic, paleogeographies and morphologies, covering mainly cycles associated with fluvial, deltaic depositional systems and shallow platform. In addition to the possible small individual thicknesses of each cycle, the petrophysical characteristics of the BCGS reservoirs are shown to be dominantly described as tight sands, forming another challenge for the seismic response, both for its exploration and for its production. An example of a challenge for the seismic response is the spatial definition of the physical boundaries (or vertical boundaries) between the upper aquifer and the zone of anomalous pressure in the reservoirs. Limits that generally do not respect the stratigraphic distribution geometry of the reservoirs, and which physically limits the gas accumulations, as well as the anisotropies involved and the presence of natural fractures. All these themes refer to both the state of the art of knowledge and specific seismic processing and interpretation methods, as well as to the theoretical and practical limitations of the seismic data in the vertical resolution and the ability to discriminate small thicknesses of reservoirs, anomalies and distribution of natural fractures that can be understood from the seismic data available in each basin. In this study we analyse an area of Potiguar basin as a possible BCGS, as described in the following item.

\section{Geological Setting}

The Potiguar Basin is located at the eastern end of the equatorial Brazil, comprising part of the states of Rio Grande do Norte and Ceará, as well as their continental shelves. The basin is limited to the South and West by rocks of the crystalline basement, North and East by the Atlantic Ocean and, to the Northwest, by the Ceará Basin. It covers an area of approximately $48,000 \mathrm{~km}^{2}$.

According to Souza (1982), the basin is related to the different phases of its tectonic evolution, being the Pendencia formation, from Neocomian age, the focus of this study, associated with the rift phase. In the more basal sedimentary sections of this formation, the target is the lacustrine sedimentation associated with deposits of alluvial fans and fan deltas, generated in the faulted margin and in the flexural margin. 


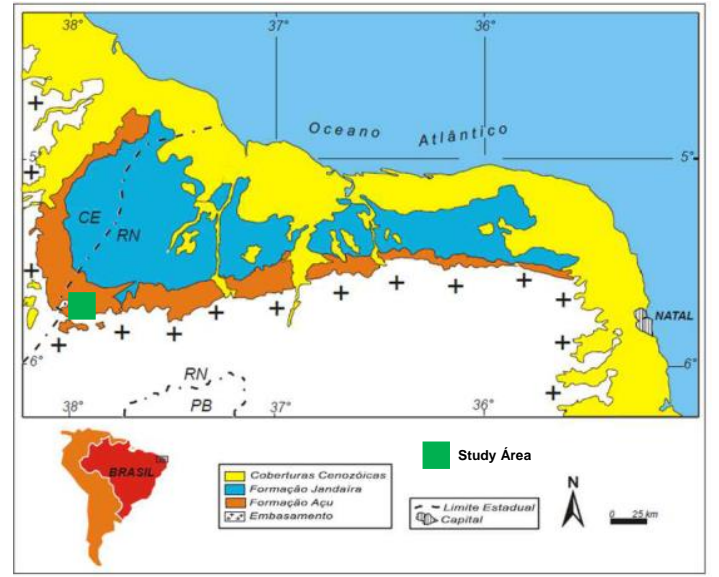

Figure 1 - Localization map of Potiguar basin and study area.

In the higher structural portions of the basin, the sedimentation of Pendencia formation is predominantly fluvio-deltaic, with sedimentation reduced to isolated sections in the basin. The model of a BCGS recommends the existence of accumulations in the terrestrial part of the Potiguar basin, which occur regionally disseminated and independent of conventional controls.

\section{Seismic Results}

Here in this work, the first geoscientific orientation for the definition of seismic data factors that can technically support a study of low permeability reservoirs such as in the Pendência formation, is an analysis of seismic heterogeneities that can be defined internally for such formation. The purpose of this analysis is to define which heterogeneities would be associated with fractures and what would be their geometries and the spatial reach of each zone densified by regions of such fractures. Whichever algorithm is adopted to obtain subtle structural discontinuities in low permeability reservoirs, the most critical qualitative factor is defined by the observation of its ability to maintain the continuities of the seismic events associated with the more ductile sedimentary sequences and, at the same time, to highlight structural discontinuities that indicate areas that may be associated with more brittle (vertically more discontinuous) regions, which would be related to faults and zones of more vertical fractures.

Lira et al (2018) present an important result of the application of the algorithm Minimum Similarity Accumulation (MSA), which determines discontinuities in seismic data through similarities between adjacent traces. This algorithm enhances the perception about continuity of the seismic events associated with the more ductile sedimentary sequences of the Pendence formation and, especially, highlights structural discontinuities associated with more brittle regions. Figure 2 illustrates a seismic line from the $3 D$ data in the studied area, pre-stack timemigrated (PSTM), wit hthe action of MSA over the original amplitude data. In this seismic line, one can observe the main classical architectural elements of a graben in the Potiguar basin and some important structural discontinuities can also be observed, mainly those more verticalized, that permeate most of the layers in the basin.

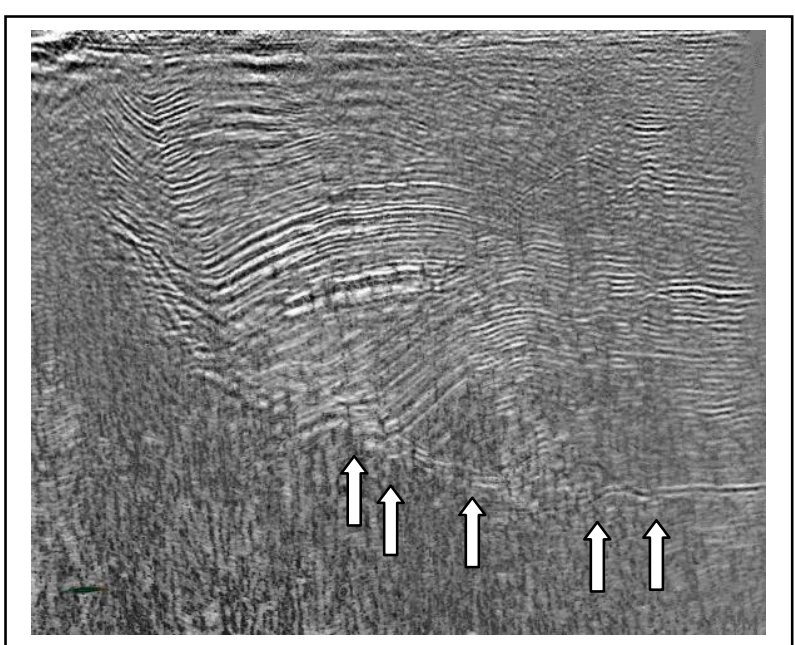

Figure 2 - 3D PSTM seismic section with MSA in the Potiguar basin associated to sedimentary sequences of the Pendência formation. The white arrows point out some sets of probable zones of fractures, which are also defined from the basement and that propagate internally in the sedimentary sequences of the Pendence formation. These regions are conventionally better imaged by geometric attributes and vector coherence of the amplitudes in 3D data.

Figure 3 shows the result of applying the MSA algorithm on data equivalent to the same line shown in Figure 2, in this case applied after an iterative deconvolution. It is important to observe the continuity of the seismic events associated to the more ductile sedimentary sequences of the Pendence Formation (light gray shades) and the enhancement of the structural discontinuities of the zones associated with more brittle regions (dark gray shades). In this work, we highlight results of amplitude treatments that further optimize the response of detection algorithms of subtle structural heterogeneities that are correlated to TGR or BCGS low permeability reservoir systems. This optimization should consider what the amplitude thresholds in which the main coherent and inconsistent noises need to be attenuated so that a given algorithm can succeed in detecting effective fracture zones.

As a consequence of this same 3D data treatment, seismic facies can be selected and grouped to define sweet spots that have the best petrophysical characteristics and indicate the main accumulations of hydrocarbons in TGR or BCGS reservoirs. 


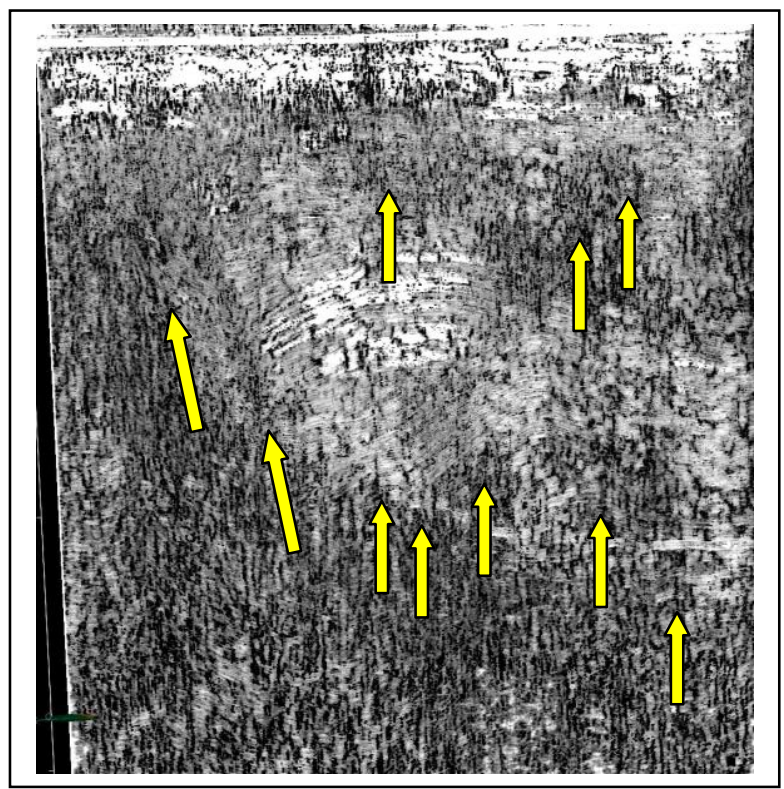

Figure 3 - Results of the application of the MSA algorithm on the data equivalent to the $3 D$ seismic line shown in Figure 2, now with iterative deconvolution. The yellow arrows indicate the enhancement of faulted zones and fractures in relation to the image shown in Figure 3.

Figure 4 shows, in orange and yellow colors, the detection of reconstructed seismic bodies from the spectral dissociation of the same 3D seismic data from the Potiguar basin, mentioned above, in the frequency of $22.7 \mathrm{~Hz}$. They show the tectonic influence over the sediments after their deposition along Neocomian channel systems. This seismic reconstruction is correlated to sandstones bodies with low permeability reservoirs and is tied by area wells.

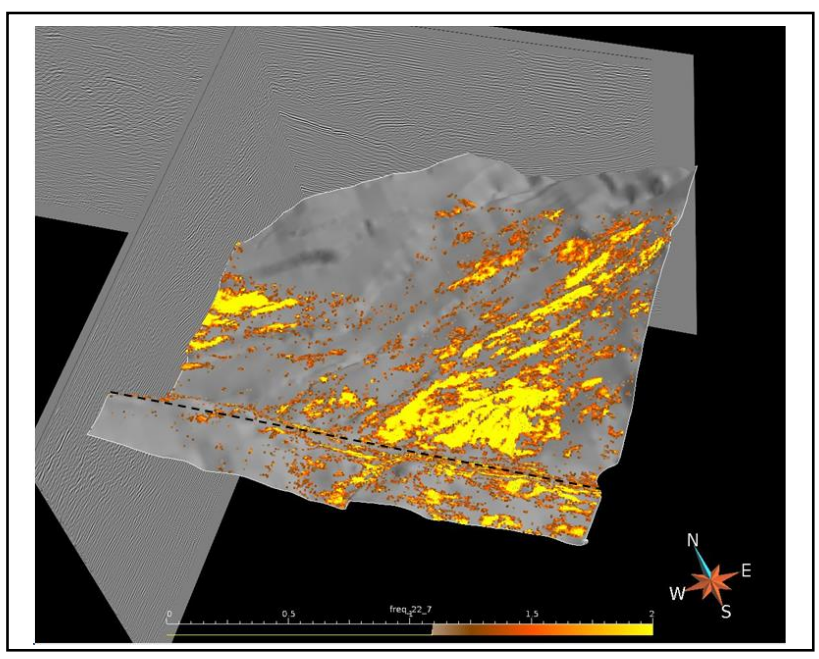

Figure 4 - Reconstruction of seismic bodies from the spectral dissociation of the $3 D$ seismic data in the frequency of $22.7 \mathrm{~Hz}$, to define sweet spots for TGR or BCGS type reservoirs.

\section{Conclusions}

Seismic identification of fractures and sweet spots using conventional $3 \mathrm{D}$ data is a challenge due to its intrinsic resolution for deep geological targets. We applied methods for detection of structural continuities and discontinuities, looking for zone of fractures using conventional amplitudes for geometric and textural interpretation to predict gas reservoirs and brittle zones. Knowledge about the occurrence of natural fractures helps to define the sweet spots, which can vary along a basin, and also to optimize the location of producing wells. Pendencia formation was analysed to illustrate concepts and performance of the applied algorithms based on main parameters supported by 3D seismic amplitudes. The choice of seismic amplitude levels to be interpreted is considered the key to derive true features of heterogeneity or homegeneity for both fractures and sweet spots.

\section{Acknowledgments}

The authors thanks to Petrobras for the permission to publish this paper and also to the previous geoscientists from Petrobras who worked in the study area in Potiguar Basin.

\section{References}

LAW, B. E., Basin-centered gas systems: AAPG Bulletin, v. 86, p. 1891-1919. 2002.

LIRA, J.E.M.; SANTOS, R. A.; BULHÕES, F.C.; FERREIRA, G.D.; TANAKA, A.; CARVALHO, J.G. and BARRETO. A.C.. Detecção de Falhas e Fraturas em Reservatórios de Baixa Permeabildiade Utilizando Atributos Geométricos. VIII Simbgf - SBGf - Pará Brazil. 2018

MECKEL, L. D., and THOMASSON, M. R..Pervasive tight-gas sandstone reservoirs: An overview, in $S$. P.Cumella, K.W. Shanley, andW. K.Camp, eds. , Understanding, exploring, and developing tight-gas sands - Vail Hedberg Conference: AAPG Hedberg Series, no. 3, p. 13-27. 2008

POPOV, M. A., NUCCIO V. F.; DYMAN, T.S.; GOGNAT, T.A; JOHSON, R.C.; SCHMOKER J.W.; WILSON M.S., and BARTBERGER, C..Basin-centered gas systems of the U.S.: U. S. Geological Survey Open-File Report, 2000, http://pubs.er.usgs.gov/publication/ofr2001135.

SOUZA, S. M.; Atualização da litoestratigrafia da bacia Potiguar. In: SBG/BA-SE, Congresso Brasileiro de Geologia, 32, Salvador, Anais p.509-592, 1982.

TANER, M.T.; KOEHLER, F. and SHERIFF, R.E.. Geophysics, Vol,44, n.6, p. 1041-1063, 1979 